\title{
INTERVENÇÃO COM FAMÍLIA DE CRIANÇA COM DEFICIÊNCIA FUNDAMENTADA EM UM MARCO TEÓRICO DESENVOLVIDO COM BASE NO MODELO DE VULNERABILIDADE E RESILIÊNCIA
}

\author{
Maria Angélica Marcheti \\ Universidade Federal de Mato Grosso do Sul \\ Campo Grande, Mato Grosso do Sul \\ E-mail: mamarcheti@gmail.com
}

\section{Myriam Aparecida Mandetta}

Universidade de São Paulo

São Paulo, São Paulo

E-mail: mymandetta@gmail.com

Resumo: No contexto da deficiência, a família vive conflitos no manejo da situação desencadeada na interação com a família, com a deficiência e com a equipe multiprofissional, causando profundo sofrimento, alterando história e relações familiares. A estruturação de uma proposta de intervenção com essas famílias para apoiar seus esforços e fortalecer a resiliência torna-se um desafio. Objetivo: apresentar a construção do Marco Teórico que fundamentou o Programa de Intervenção com Família no Contexto da Deficiência Mental e as intervenções direcionadas à família. Metodologia: O Marco Teórico foi baseado nos pressupostos do Interacionismo Simbólico, Vulnerabilidade da Família e Resiliência. Resultados: O Marco Teórico proposto visa direcionar o olhar dos profissionais para a experiência da família e para o planejamento de intervenções que minimizem a vulnerabilidade e potencializam sua resiliência.

Palavras-chave: enfermagem familiar, estudos de intervenção, resiliência psicológica, crianças com deficiência.

\section{INTERVENTION WITH FAMILIES OF CHILDREN WITH DISABILITIES BASED ON A THEORETICAL FRAMEWORK DEVELOPED ON VULNERABILITY AND RESILIENCE MODEL}

Abstract: The context of a child with disabilities triggers deep suffering in the whole family, because it changes the history and the family's interactions. The proposal of an program of intervention with these families to support their efforts and strengthen their resilience becomes a challenge for nurses. Objective: to present the theoretical foundation of an Intervention Program in the Family in the Context of Mental Disability/PIFCDM. Methodology: The theoretical was built based on the integration of the assumptions of Symbolic Interactionism, the Vulnerability of the Family Concept and the Resiliency Model, to guide the intervention program to assist families who experienced the mental disability of a loved one. Results: the theoretical foundation offers elements for the nurse to propose interventions in the family in the context of disability of a member.

Keywords: family nursing, intervention studies, psychological resilience, children with disabilities.

Recebido em 28/11/2016. Publicado em 31/12/2016. 


\section{INTRODUÇÃO}

Para promover o cuidado da família é preciso proporcionar-lhe um contexto relacional, no qual seus membros consigam manejar as situações e os conflitos que os desafiam ao longo da vivência da deficiência e ou condição crônica de saúde de um membro. Desta maneira, poderão se engajar em um movimento de busca de respostas frente às demandas emergentes na situação vivenciada assim como novas maneiras para lidar com a situação.

Também é preciso que o enfermeiro compreenda que a família é a mais constante unidade de saúde para seus membros. Desta maneira, a assistência à família como unidade de cuidado implica conhecer como cada uma cuida e identifica as suas forças, as suas dificuldades e os seus esforços para partilhar as responsabilidades (ANGELO; BOUSSO, 2001).

Diante de determinadas situações ou fases da trajetória familiar, em especial em vivências de doença grave, de deficiência ou malformação congênita e de hospitalização prolongada, a família percebe-se fragilizada de maneira a comprometer sua capacidade para cuidar de seus membros e para tomar decisões. O impacto emocional do nascimento de uma criança com algum tipo de deficiência ou condição crônica de saúde, assim como o diagnóstico dessa condição traz consigo, seja na hora do nascimento ou no momento de sua identificação, desilusão e sofrimento na família (MARCHETI; MANDETTA, 2016).

É evidente que o sofrimento vivenciado pela família no contexto da deficiência de um filho, marca profundamente a vida e envolve todos os seus membros, de modo a alterar a sua história e as interações familiares. Esse acontecimento demanda da família uma série de mecanismos de ajustes para o enfrentamento e a incorporação da nova situação provocando alterações na dinâmica familiar (SUNELAITIS; ARRUDA; MARCON, 2007; BARBOSA; CHAUD; GOMES, 2008; HOLANDA; COLLET; COSTA, 2008).

A situação de deficiência impõe que a família modifique sua maneira de funcionar. Nessa experiência, existem as que dão conta do desafio e das novas demandas que surgem, e outras encontram maior dificuldade e não conseguem organizar-se na situação. Muitas famílias dão mostras de desesperança, tristeza, desânimo e cansaço na jornada com a criança e, por vezes, a sua estrutura é ameaçada e a sua capacidade de manejar e reagir, frente às situações de crise potencialmente desestruturadoras, encontra-se enfraquecida. Frente às novas situações exigidas 
pela condição de cuidados e reabilitação da criança, a família repensa a sua estrutura e forma organizacional enquanto grupo. O cuidado à criança pode exigir a presença constante de uma pessoa que acaba por se afastar de sua rotina diária, profissão e da própria família.

A convivência com o filho com deficiência modifica a vida familiar, gerando conflitos na relação conjugal e na relação com os demais membros da família, alterando os papéis e os padrões organizacionais da família. O impacto causado por esse evento mostra-se como um processo doloroso para a família que se vê despreparada para enfrentar ou lidar com essa experiência e para manejar os conflitos e as interações familiares (BARBOSA, 2000). Nessa experiência a família tem uma sobrecarga adicional em todos os níveis: social, psicológico, financeiro e com relação à demanda de cuidados e reabilitação da criança e necessita acessar redes de suporte social disponibilizadas na comunidade (BARBOSA; PETTENGILL; FARIAS; LEMES, 2009). A família precisa aprender a conviver com as limitações impostas pelo contexto, com o medo da piora do quadro de saúde da criança, além do preconceito vindo da sociedade. Vivencia dúvidas sobre os cuidados exigidos pelas condições de saúde e reabilitação do filho e uma sobrecarga de demandas no cotidiano, com falta de recursos financeiros e de transporte (GUILLER; DUPAS; PETTENGILL, 2009).

Um fato importante que contribui e dá origem ao sentimento de vulnerabilidade é que as famílias têm recebido pouca informação sobre a deficiência do filho e suas implicações para seu desenvolvimento. Elas precisam ser orientadas e fortalecidas para o cuidado dele, a fim de que possam estabelecer interações e relações saudáveis e para manter o equilíbrio do grupo familiar (PEREIRA-SILVA; DESSEN, 2002; HOLANDA; COLLET; COSTA, 2008; MARCHETI, 2012). É comum, na experiência da família com o filho e com as demandas e desafios desencadeados pelo contexto da deficiência dele, identificar o evidente distanciamento dos profissionais de saúde. O desrespeito oculto e silencioso é percebido pela família em atitudes de pouco ou nenhum acolhimento. Diante dessa realidade a família torna-se desprovida de apoio para o enfrentamento das situações emergidas nesse contexto intensificando o sofrimento (MARCHETI, 2012).

O sofrimento da família na experiência da deficiência do filho desde o momento em que se depara com a suspeita do diagnóstico revela-se como uma vivência central, e evidencia-se como um aspecto relevante da família nesse contexto. 
Nessas famílias, o sofrimento profundo surge também da perda de significado, sentido e esperança. O sofrimento é desafiador para a família que precisa desenvolver a consciência de que ela não poderá ser substituída nesse processo, no qual vive uma adversidade que lhe é imposta, porém, que é sua e, deste modo, será necessário que a enfrente. Entretanto, é preciso ajudá-la a passar pelo sofrimento que lhe é peculiar e único, e pelas modificações não desejadas que o contexto Ihe causou, e ampará-la a prosseguir por meio deles. Conforme Wright (2005), reduzir ou aliviar o sofrimento é a essência e o coração da prática clínica do enfermeiro.

A vulnerabilidade e o sofrimento da família ao viver a experiência de ter um filho com deficiência, permeada pela ausência de informações, pelo distanciamento do profissional de saúde e dificuldade de uma abordagem profissional que olhe para a família no sentido de ajudá-la a aliviar o sofrimento e a instrumentalizá-la para o manejo das situações e interações familiares é uma realidade.

Entretanto, é cada vez mais evidente na literatura que as famílias dessas crianças demonstram força e articulam as contribuições positivas da deficiência à vida e ao bem estar de toda a família (SCORGIE, WILGOSH; SOBSEY, 2004; HASTINGS; BECK; HILL, 2005). Porém, esse contexto exige que a família modifique sua maneira de funcionar.

Apesar dos avanços no conhecimento sobre a experiência de sofrimento da família no contexto da deficiência e do movimento de pesquisadores interessados em estudos de intervenções de enfermagem com família, estudiosos nessa temática observam que há ainda uma lacuna em relação a estudos de intervenção, que são imprescindíveis para promover o cuidado da família, e ajudá-la a se fortalecer, a manejar as interações familiares perturbadas por esse evento e aliviar o sofrimento (SVAVARSDOTTIR, 2006; BELL; WRIGHT, 2007; GANONG, 2011).

Wright, Leahey (2008) evidenciam que as intervenções de enfermagem são as respostas da enfermeira às famílias e têm por objetivo diminuir ou aliviar o sofrimento e ajudar a família a promover mudanças. Para elas, a intervenção em um sistema familiar de modo a promover ou facilitar a mudança é o aspecto mais desafiador do trabalho clínico com as famílias, pois proporciona um contexto apropriado no qual a família pode fazer as alterações necessárias. 
Tendo feito tais ponderações, questionamo-nos sobre quais intervenções de enfermagem poderão ser úteis para assistir e apoiar a família em contextos de deficiência e condição crônica de saúde? Como ajudar famílias a lidar com as situações advindas dessa experiência? Como expandir possibilidades e abrir espaços, para que a família considere maneiras alternativas de interagir $e$ reagir às situações? Como um trabalho sistematizado com famílias que vivenciam o cotidiano com um filho com deficiência, poderá possibilitar ao sistema familiar seu fortalecimento, o desenvolvimento de processos de resiliência e o ajustamento de seus membros às situações surgidas em sua trajetória com ele?

É preciso que a enfermeira utilize ferramentas conceituais que possam direcionar intervenções efetivas às famílias de crianças com deficiência. Desse modo, esse estudo se propôs a apresentar a construção do Marco Teórico que fundamentou o Programa de Intervenção com Família no Contexto da Deficiência Mental/PIFCDM, construído para promover as forças e potenciais da família vivenciando o contexto da deficiência e fortalecer sua resiliência, e as intervenções direcionadas à família.

\section{PERCURSO METODOLÓGICO}

\subsection{Marco Teórico do Programa de Intervenção com Família no Contexto da Deficiência Mental}

A construção de um Marco Teórico configurou-se como uma etapa essencial para a proposição de um Programa de Intervenção com Família no Contexto da Deficiência Mental - PIFCDM. Ela foi realizada com base na articulação teórica entre os conceitos do Interacionismo Simbólico, do Modelo de Vulnerabilidade da Família proposto por Pettengill (2003) e do Modelo de Resiliência de Walsh (2005), considerando que tais perspectivas guiam nossa percepção de mundo, dando-lhe sentido e explicação. Também, a nossa prática e compreensão da experiência da família no contexto da deficiência mental do filho, objeto de estudos realizados, contribuíram com o processo de construção deste Marco Teórico.

A seguir, apresentamos as ideias centrais dos referenciais acima citados que consideramos essenciais para fundamentar o PIFCDM.

\subsubsection{Interacionismo Simbólico - IS}


O IS é uma perspectiva útil para compreensão da ação humana, enfoca o comportamento humano individual e grupal, tendo como princípio a compreensão do processo vivido. Nesse referencial, o ser humano define e age na situação de acordo com significações ali construídas, que emergem na interação social e exercem influência nas atitudes, formas de organização e relações intra e interpessoais estabelecidas (BLUMER, 1969).

Assim, segundo Blumer (1969) o IS baseia-se em três premissas básicas:

- Os seres humanos agem em relação às coisas apoiado no significado que estas têm para eles; tais coisas incluem tudo aquilo que os homens podem perceber no mundo;

- Os significados das coisas derivam das interações sociais que uns têm com os outros;

- Esses significados são modificados em um processo interpretativo usado pela própria pessoa ao lidar com as coisas que encontra.

A definição simbólica da situação, isto é o significado atribuído pelo ser humano nas interações que estabelece consigo, o outro e o mundo, conduz suas ações e reações. A interação implica pessoas agindo em relação a outras, percebendo, interpretando e atuando novamente.

Pensando em família interagindo na situação, Angelo (1997) realizou uma aproximação entre o IS e a família trazendo contribuições para se "pensar a família interacionalmente". Conforme a autora, a família pode ser considerada como pessoas em interação simbólica: [...] "Família é um grupo de indivíduos em interação simbólica, chegando às situações com os outros significantes ou grupos de referência, com símbolos, perspectivas, self, mente e habilidade para assumir papéis".

A família está em constante interação simbólica com seus membros, com a equipe profissional, com a sociedade e com as situações emergidas em seu cotidiano e nos processos interacionais modificados pela condição de deficiência. Os significados resultam das interações que a família tem com os elementos presentes na experiência de deficiência mental do filho e toma decisões sobre como agir e reagir às situações impostas por esse fenômeno.

Ao vivenciar a experiência de um filho com deficiência mental, a família entra na situação, estabelecendo como objetivo a reestruturação da dinâmica e do funcionamento da família, investindo na capacitação do filho para agir em sociedade. Interage com as perspectivas da 
equipe, da família e da criança, definindo para o self os objetos relevantes na situação, trazendo para o presente as experiências vividas no passado ou na vida familiar e considera as possibilidades do futuro, temendo as consequências. Com base nas interações e nos significados que a família atribui à experiência, ela toma decisões sobre como agir, reagindo à situação.

Assim, guiadas pelo pensamento interacionista, consideramos que o conceito de definição simbólica é central na experiência da família no contexto da deficiência mental, pois a família atribui significados à experiência da condição de deficiência mental, que direcionam sua maneira de agir no mundo, isto é, como conduz e maneja a vida familiar nesse contexto. Tais significados podem ser comuns e diferentes a cada grupo familiar e para cada membro da família, por causa do processo interno de cada pessoa.

\subsubsection{Modelo de Vulnerabilidade da Família}

O Modelo de Vulnerabilidade da Família foi construído com base na análise crítica da literatura e na experiência da família com uma situação de doença e hospitalização de um filho. Nesse contexto, a vulnerabilidade da família é definida como um sentimento de ameaça à sua autonomia, em razão das pressões desencadeadas pela interação com a doença, com a unidade familiar e com a equipe de saúde (PETTENGILL, 2003; PETTENGIL; ANGELO, 2005; PETTENGILL; ANGELO, 2006).

Os atributos definidores da vulnerabilidade estão relacionados ao contexto da doença que gera incertezas, impotência, ameaça real ou imaginária, dúvidas e insegurança, exposição ao dano, temor do resultado, submissão ao desconhecido e expectativas de retornar à vida anterior. Ao contexto da família com desequilíbrio em sua capacidade de funcionamento, tendo desestrutura, distanciamento familiar, alteração na vida e na rotina familiar, ausência de suporte social e falta de apoio da família, sentimento de abandono e conflitos familiares. Ao contexto da equipe marcado pela falta de diálogo, a família não se sente ouvida pela equipe nem percebe seu apoio, desrespeito e afastamento de seu papel (PETTENGILL, 2003). Como consequência, a família alterna momentos em que não consegue fazer nada, com outros em que tenta resgatar sua autonomia, sendo, portanto, um movimento dinâmico e contínuo que atribui uma transitoriedade a seu sentimento de vulnerabilidade ao longo da experiência. 
Na experiência vivida pela família no contexto da deficiência mental, a ameaça a sua autonomia é identificada baseada nas interações com a própria condição de deficiência, com a família, e com a equipe de saúde, conforme evidenciado na literatura (MARCHETI, 2012). Os atributos conceituais de vulnerabilidade da família são relevantes para conduzir o processo teórico de compreensão da definição simbólica que a família faz da condição de deficiência mental e como age e reage na situação.

\subsubsection{O Modelo de Resiliência}

A estrutura conceitual de resiliência da família, proposta por Walsh (2005), permite a identificação de elementos característicos da resiliência que podem ser úteis para capacitar a família frente às adversidades, denominados processos-chave, com o objetivo de promover o fortalecimento da família que se encontra esgotada em suas forças e frustrada em sua trajetória com as situações de doença.

Neste modelo, a resiliência é definida como a habilidade da família suportar a dificuldade e o inesperado frente às adversidades e tornar-se forte e organizar-se. Caracteriza-se pela sua capacidade de responder de forma positiva às demandas da vida quotidiana, apesar das adversidades que enfrenta. Uma abordagem da resiliência familiar permite-nos deixar de enxergar as famílias como prejudicadas e passar a entender como elas são desafiadas pela adversidade, e afirma o potencial da família para o auto-reparo e para o crescimento a partir da crise.

A estrutura conceitual compreende três domínios: sistema de crenças, padrões organizacionais $e$ processos de comunicação, que proporcionam uma estrutura favorável à identificação das potencialidades e vulnerabilidades da família, sendo úteis para orientar a avaliação do funcionamento familiar, proporcionar coerência ao planejamento de intervenções, pois ajudam a encontrar os processos-chave para fortalecer a resiliência familiar.

As crenças estão no âmago de quem somos e da maneira como entendemos e extraímos sentido da nossa experiência. Os sistemas de crenças abrangem amplamente valores, convicções, atitudes, e suposições que se misturam para formar um conjunto de premissas básicas que desencadeiam reações emocionais, informam decisões e guiam ações. Os sistemas de crenças familiares 
proporcionam coerência e organizam a experiência para possibilitar aos membros da família extraírem sentido das situações de crise.

Os padrões organizacionais familiares dão apoio à integração da unidade familiar. Eles definem os relacionamentos e regulam o comportamento e são mantidos por normas externas e internas, reforçadas por sistemas culturais e de crença familiar.

Os três domínios de funcionamento familiar proporcionam uma estrutura favorável à identificação das potencialidades e vulnerabilidades da família, sendo úteis para orientar a avaliação do funcionamento familiar, proporcionar coerência ao planejamento de intervenções, pois ajudam a encontrar os processos-chave para fortalecer a resiliência familiar.

\subsection{Marco Teórico do Programa}

O Marco Teórico do PIFCDM é composto por seis dimensões interrelacionadas que guiam a compreensão da definição simbólica da experiência de sofrimento e vulnerabilidade da família, assim como sua capacidade para o enfrentamento, direcionando as intervenções com o objetivo de ajudá-la a extrair potencialidades para lidar com as situações emergidas pela deficiência, adaptar-se ao futuro imediato e a reorganizar a vida em longo prazo.

A seguir apresentamos as dimensões que compõe o Marco Teórico:

Definição Simbólica: A definição simbólica permite compreender como a família significa e percebe a experiência na condição de deficiência mental do filho, e guia as ações e reações da família ao viver a experiência.

Dimensão 1: A compreensão da interação da família com a condição do filho permite identificar os elementos que contribuem para sua vulnerabilidade relacionados à deficiência mental, desencadeados com base no diagnóstico ou mesmo na suspeita do diagnóstico, tais como: incerteza, impotência, ameaça real ou imaginária, exposição ao dano, temor do resultado, submissão ao desconhecido e expectativas de retornar à vida anterior.

Dimensão 2: A compreensão da interação da família com a própria unidade familiar em razão da condição de deficiência mental fornece evidências sobre a maneira como a 
família lida no ambiente intrafamiliar com a situação. Nesse contexto interacional, a vulnerabilidade da família manifesta-se pelo desequilíbrio na capacidade de funcionamento, desestrutura, distanciamento, alteração na vida familiar e conflitos intrafamiliares.

Dimensão 3: A compreensão da interação da família com a equipe revela como ocorrem os processos de aquisição de informações, acolhimento, participação nos cuidados e nas tomadas de decisão. Quando essa interação é marcada por conflitos com falta de diálogo, desrespeito e afastamento da família em relação a seu papel, a vulnerabilidade da família é intensificada.

Dimensão 4: O sistema de crenças da família fornece pistas sobre o que a família acredita e valoriza no contexto vivido e os elementos que influenciam suas percepções. A identificação das crenças facilitadoras pode ser fundamental para desenvolver e fortalecer o potencial da família no enfrentamento dos desafios emergidos pelo contexto da deficiência, pois abrangem valores, convicções, atitudes e suposições que formam um conjunto de premissas básicas que desencadeiam reações emocionais, informam decisões e guiam as ações da família.

Dimensão 5: Os padrões organizacionais oferecem condições para a compreensão de como a família da criança com deficiência mental pode mobilizar recursos, resistir ao estresse e reorganizar-se para adaptar ao contexto e para lidar de maneira eficiente com as crises e a persistente adversidade advinda dessa condição.

Dimensão 6: Os processos de comunicação que a família estabelece são fundamentais para a compreensão de como ela lida com a adversidade. Processos de comunicação eficazes podem facilitar o funcionamento familiar ao potencializar a competência de seus membros, para expressarem sentimentos e emoções emergidos pelo contexto da deficiência mental do filho, para satisfazer novas demandas na situação de crise provocada pelo contexto e para negociação dos processos de mudanças na família.

A definição simbólica da família nesse contexto é construída com base na interação com a deficiência mental, com a família e com a equipe de saúde. Tais interações podem desencadear e 
intensificar seu sentimento de vulnerabilidade, pois se percebe sem autonomia para lidar com as demandas que se sobrepõem. A compreensão do sistema de crenças, dos padrões organizacionais e dos processos de comunicação são fundamentais para identificar as potencialidades da família e sua capacidade de resiliência.

A aplicação do Marco Teórico direciona o olhar para a experiência da família e para o planejamento de intervenções de enfermagem com o objetivo de minimizar a vulnerabilidade e potencializar sua resiliência por meio de mudanças promovidas pela própria família.

\section{RESULTADOS E DISCUSSÃO}

\subsection{Programa de Intervenção com Família no Contexto da Deficiência Mental}

O Programa de Intervenção na Família no Contexto da Deficiência Mental - PIFCDM baseado no Marco Teórico apresentado trata-se de uma estrutura organizada para direcionar a intervenção com família da criança com deficiência mental, que se encontra em situação de vulnerabilidade e sofrimento desencadeados nas interações que estabelece com a condição da criança, com a família nuclear e ampliada e com os profissionais e instituições de atendimento especial de ensino e saúde.

As intervenções propostas são ferramentas indispensáveis para a enfermeira desenvolver uma prática avançada com famílias. As intervenções do PIFCDM visam a criar e potencializar recursos na família, para que ela possa lidar mais efetivamente com o sofrimento intensificado na experiência da deficiência e da condição crônica de saúde da criança e do adolescente e recuperar-se de maneira fortalecida, tanto individualmente como enquanto um sistema relacional; estimular a capacidade da família para enfrentar situações de crise imediata, aumentando sua competência para enfrentar desafios futuros, e fortalecer os processos interacionais fundamentais para estimular o enfrentamento, a recuperação e a resiliência.

Assim, as ações envolvem ajudar a família a recuperar-se de maneira fortalecida, estimular sua capacidade para enfrentar situações de crise imediata e desafios futuros, e a recuperação de sua resiliência.

\subsection{Participantes do programa e seu impacto na família}


Famílias vivenciando o contexto da deficiência mental de um membro, criança ou adolescente, com manifestação verbal e/ou não verbal de dificuldade para manejar a situação, em relação ao cuidado da criança/adolescente e/ou no relacionamento intrafamiliar foram convidadas por meio de reuniões e encaminhamento dos profissionais de saúde das instituições e também por meio de cartazes fixados nos ambientes de permanência delas em instituições de reabilitação.

As famílias são convidadas a participar de uma reunião, com o objetivo de aproximação e para apresentação do programa e seus objetivos. Após essa reunião, as famílias que desejam participar do PIFCDM agendam a entrevista de iniciação.

\subsection{Intervenções realizadas com uma família participante do programa}

Apresentamos o caso da família HM, atendida no PIFCDM, destacando as dimensões do Marco Teórico exploradas e as reflexões ou decisões das autoras.

\section{Família HM}

Família composta por H. sexo masculino, de 40 anos, cursou o Ensino Fundamental, tabagista, passa a semana trabalhando na fazenda onde é motorista, seus pais são vivos, e ele tem mais 13 irmãos. Também compõe a família M., sexo feminino, de 42 anos, trabalhadora do lar, possui o Ensino Fundamental, foi criada pela avó paterna, quando sua mãe deixou a família. H. e M. estão casados há cerca de 20 anos e faz parte da família, J., sexo masculino, 23 anos, filho de M., auxiliar administrativo, cursa administração na faculdade e mora em uma cidade próxima a capital, e HC., sexo masculino, 17 anos, com deficiência mental, filho do casal, aluno da Associação Pestalozzi, é acompanhado por médico neurologista, faz uso de medicamentos diariamente e recebe o benefício previdenciário. Quando a família inscreveu-se no Programa/PIFCDM, HC. vivenciava o despertar de sua sexualidade, o interesse por 'namorar' e apresentava comportamento agressivo, especialmente em seu relacionamento com a sua mãe. A família buscava ajuda para manejar a situação e possuía crenças diferentes sobre a situação. H. manifestava a intenção de levar o filho em uma 'casa de mulheres' e M. discordava dessa ideia de maneira incisiva, temendo pela aproximação do filho com 'mulheres da vida' e vindo a sofrer por envolvimento emocional. M. repreendia, por vezes usando força física, toda expressão do filho com relação ao seu interesse 
pelas meninas o que o deixava agressivo. M. acreditava que pessoas com deficiência não desenvolviam sua sexualidade e o interesse por um relacionamento amoroso.

Definição simbólica: crenças restritivas da família sobre o desenvolvimento da sexualidade do filho com deficiência mental que determinavam ações de represálias ao comportamento do filho.

A família verificou o cartaz convite afixado na instituição e, em razão dos conflitos no manejo do relacionamento familiar, inscreveu-se no PIFCDM. Participou de uma reunião convite na própria instituição, momento em que foi esclarecida sobre o funcionamento do mesmo. Após os esclarecimentos sobre o programa, a família concordou em participar dos encontros, assinou o Termo de Consentimento Livre e Esclarecido e o início dos encontros foi agendado em conjunto com ela.

A família ingressou no PIFCDM e após oito encontros no programa, recebeu alta e participou da entrevista de finalização três meses depois.

\section{Identificação das interações e definições simbólicas da família}

Definição Simbólica da experiência da família: crenças restritivas da família sobre o desenvolvimento da sexualidade do filho com deficiência mental que determinavam ações de represálias ao comportamento do filho.

Forças: A família interage com seus membros, mantendo vínculos fortes e de ajuda. Proporciona atividades de desenvolvimento do filho com deficiência mental, colaborando com a equipe de saúde e escolar no que lhes é solicitada. A família percebe-se capaz para manejar outras situações do contexto de deficiência do filho.

Demandas e desafios: Conflitos nas interações familiares: entre o casal e o filho HC especialmente com relação ao comportamento e interesse por questões da sexualidade dele. Crenças restritivas que desencadearam reações emocionais e comportamentais na educação do filho e no manejo do despertar de sua sexualidade. Acúmulo de tensões e interações negativas que impedem a expressão de sentimentos e emoções, e o manejo bem sucedido da situação. Desequilíbrio na capacidade de manejar o funcionamento familiar e o comportamento do filho. Necessidade da 
família em ser orientada e informada sobre a deficiência mental e o desenvolvimento da sexualidade do filho.

Hipótese de sofrimento: As forças da família estavam sendo desafiadas pelo contexto da deficiência mental do filho e o despertar de sua sexualidade, que desencadeou conflitos nas interações familiares, afastamento entre seus membros e agressões físicas. Os pais apresentavam dificuldades no manejo da situação, com a aplicação de punições ao jovem com deficiência que repercutiam em crise no relacionamento do casal, e entre eles e o filho; alteração nos processos de comunicação e distanciamento entre os membros da família. As hipóteses de sofrimento de acordo com Marcheti (2012) ficaram assim apresentadas: Demandas emocionais e relacionais da família na interação com o contexto da deficiência mental do filho, por desconhecimento e incertezas, sentimento de ameaça e impotência, e submissão ao desconhecido; Demandas na capacidade de funcionamento da família com conflitos e rupturas no relacionamento familiar.

Objetivos e planos: Desenvolver habilidades na família para se fortalecer e aprender a manejar os relacionamentos intrafamiliares alterados pelo contexto de deficiência mental do filho e para a reorganização do funcionamento e da comunicação na família. Informar a família sobre a sexualidade da pessoa com deficiência mental. Encorajar a família a conversar sobre suas crenças e temores em relação ao desenvolvimento do filho e de sua sexualidade.

\section{Intervenções realizadas}

Fundamentadas pelo Marco Teórico as intervenções propostas visavam a ajudar a família a promover mudanças na maneira como significava a situação. Deste modo, foram direcionadas ao sistema de crenças da família, para promover a mudança no manejo dos relacionamentos intrafamiliares; ao padrão organizacional, a fim de que a família se reorganizasse e restabelecesse seu funcionamento; e no processo de comunicação, a fim de potencializar a competência dos membros da família para expressarem seus sentimentos. As dimensões 4, 5 e 6 do Marco Teórico guiaram o caminho para promover o fortalecimento da resiliência dessa família.

As intervenções sugeridas foram realizadas durante os encontros terapêuticos com a família. Nessas ocasiões, houve a participação do pai em três encontros, do jovem HC em um encontro e da mãe em seis encontros. 
A seguir apresentamos algumas intervenções realizadas com esta família, contendo exemplos de perguntas que favoreceram o diálogo, provocando reflexões e facilitando a participação da família. Note-se que as perguntas de intervenção apresentadas nos exemplos não se esgotam nelas mesmas, e estão disponibilizadas apenas para facilitar a compreensão da condução do processo terapêutico com essa família:

Criar ambiente dialógico para incentivar a narrativa da família sobre sua vivência. O foco foi buscar um espaço relacional em que ela mesma pudesse extravasar as emoções, compartilhar do pensar do outro, conhecer os sentimentos, a experiência e o sofrimento recíprocos, narrar os sentimentos de culpa e ressentimentos, abrindo espaço para um membro ouvir a experiência do outro. Assim, os pais podiam se abrir para se ouvirem mutuamente, e para ouvir o jovem com relação à sua compreensão sobre as mudanças que estava vivendo. Esse espaço permitiu que os membros ampliassem o conhecimento mútuo, e o extravasamento das emoções, percepções e crenças restritivas.

Perguntas de Intervenção: Conte-me como tem sido a experiência da família frente às situações impostas pela condição de deficiência mental de HC e do despertar de sua sexualidade. De que maneira vocês interpretam o comportamento do filho.? Quem de vocês tem sofrido mais com o manejo da situação? A que vocês atribuem a razão do comportamento agressivo do filho HC? Quais as atitudes de HC. que contrariam vocês? O que vocês acreditam que pode melhorar essa situação? Como você pode ajudar?

Oferta de informações e orientações sobre a sexualidade da pessoa com deficiência mental. A leitura e discussão de textos explicativos sobre a sexualidade da pessoa com deficiência foram encorajadas. Com essa intervenção, o objetivo foi oferecer condições, para que os pais compreendessem melhor sobre o desenvolvimento da sexualidade do filho e do seu comportamento e reações, e para subsidiá-los a lidar de maneira mais eficiente com as suas perguntas e expressão de interesse em relacionamentos, e a reorganizar padrões de funcionamento mais saudáveis. A dimensão da comunicação foi explorada com o objetivo de proporcionar à família maior preparo para efetuar mudanças na abordagem ao filho e no manejo das interações familiares. 
Perguntas de Intervenção: Conte-me o que vocês compreenderam sobre a leitura realizada? Como o texto ajudou vocês? O que mais chamou a atenção de vocês no texto entregue no encontro passado, conte-me por quê?

Validação e normalização de respostas emocionais emergidas na família no contexto da deficiência mental e do despertar da sexualidade do filho. O objetivo desta intervenção foi proporcionar à família a possibilidade de expressar sentimentos e temores nunca antes narrados, e potencializar suas competências para mudanças em seu processo de comunicação relacional entre os membros. A intervenção também buscou possibilitar à família a discussão sobre a existência de sentimentos negativos do casal em relação às práticas disciplinares não eficazes.

Perguntas de Intervenção: Estou entendendo que você sente-se triste quando repreende o seu filho e ele fica agressivo com você. Como você demonstra isso? Se vocês conversassem mais a respeito do despertar da sexualidade do HC e sobre a maneira de lidar com ela, como você se sentiria?

Elogio às forças, aos esforços, às realizações e às competências da família no cuidado do filho. Mostramos para a família sua capacidade de mobilizar recursos e resistir à adversidade vivida por ela na trajetória em família e com o filho com deficiência mental, e como se adaptou, com os recursos de que dispunha no contexto vivido. Foram realizadas reflexões com a família buscando evidenciar e reconhecer sua luta por recursos para garantir o crescimento e o desenvolvimento do filho com deficiência mental e sua inclusão na sociedade, e também sua capacidade para investir no cuidado de seus membros. O objetivo era reforçar o potencial da família para enfrentamento da situação atual, tendo por base seus próprios recursos.

Perguntas de Intervenção: Eu percebi que vocês não mediram esforços para proporcionar ao filho HC. condições para seu desenvolvimento e aprendizado. Conte-me quais os recursos que vocês dispuseram que consideram que os ajudaram a garantir isso a ele?

Nessa intervenção, busca-se reafirmar as potencialidades da família, ajudando-a a se perceber como uma família colaborativa e bem-sucedida no enfrentamento das situações já vividas e no enfrentamento dos atuais desafios e nos futuros.

Perguntas de Intervenção: Quais são as capacidades que vocês têm que os ajudaram a enfrentar os desafios surgidos? 
Discutir situações vivenciadas em que a família percebeu-se capaz de enfrentar seus medos e crenças e de acertar na condução da educação do filho e no manejo do relacionamento familiar e em fazer o melhor pela família. Esta intervenção buscava trazer à tona a competência da família no enfrentamento dos desafios familiares vivenciados e empoderar a família de seus próprios recursos para atuais enfrentamentos.

Perguntas de Intervenção: Percebo o quanto a história da familia trouxe sentimento de orgulho para vocês. Como essa experiência ajuda a resolver as situações e conflitos surgidos hoje na família?

Manutenção da esperança e do otimismo da família para resistir às adversidades atuais, ajudando-a a refletir sobre o contexto. Esta intervenção, guiada pelas dimensões 4 e 5 do Marco Teórico, pretendia fortalecer o potencial da família no enfrentamento dos desafios vividos pelo contexto da deficiência mental do filho, reforçando crenças facilitadoras de que eram possuidores de habilidades e forças, fortalecendo processos familiares protetores, as interações e a resiliência de todos na família.

Perguntas de Intervenção: Já houve uma época em que vocês se sentiram mais esperançosos com a situação? O que era diferente? Quem era mais otimista? O que vocês consideram que poderia ajudar a readquirir a esperança de que vocês podem vencer a situação atual?

Apoio à família para conviver com a incerteza do futuro ou de situações que não podem ser previstas ou controladas na vida do filho com deficiência mental e na vida familiar. A família pode mobilizar recursos e adaptar-se ao contexto e lidar de maneira eficiente com os desafios que possam surgir pela condição de deficiência do filho. Esta intervenção teve como objetivo identificar as habilidades do filho no cotidiano de suas interações, os potenciais da família no enfrentamento e nas lutas vividas, e mobilizar seus recursos para se adaptarem ao contexto e para lidarem com as demandas e desafios futuros.

Evidenciados o potencial e a força do filho com deficiência mental com os desafios do dia a dia e com o que já havia conquistado e superado.

Perguntas de intervenção: Vocês têm proporcionado ao HC. condições para que ele desenvolva suas habilidades e potenciais. O que mais pode ser feito para prepará-lo para o desafio atual? 
Como vocês percebem a autonomia de HC. no cotidiano das atividades dele e no manejo da própria sexualidade?

Encaminhar carta terapêutica a família para favorecer o vínculo terapêutico e testemunhar as mudanças que estavam sendo efetuadas com base na participação dela no PIFCDM. As cartas tiveram como objetivo convidar a família a refletir sobre as interações familiares, as crenças que desencadeiam suas ações e reações, sobre sua capacidade manejar a situação, e sobre sua habilidade para se abrir a novas possibilidades de diálogo e mudanças. As cartas foram relevantes para promover a resiliência da família.

\section{Mudanças realizadas pela familia}

Mudanças na Definição Simbólica da experiência da família: o bem estar da família passa a ser priorizado e as interações familiares são fortalecidas. A família compreende a necessidade do filho HC. e o despertar de sua sexualidade e abre-se para o diálogo e mudanças no manejo da situação. Toma decisões de forma participativa e dialogada em família.

Essa família teve um espaço disponibilizado para ser ouvida, refletir sobre suas interações e as possibilidades de efetuar mudanças. As dimensões do Marco Teórico guiaram a compreensão da experiência da família e possibilitaram a observação das mudanças interacionais efetuadas pela família no contexto que estão descritas a seguir.

Os pais conseguiram ressignificar suas crenças com relação à maneira de agir e de se relacionar com o filho HC., e com o despertar de sua sexualidade, o que desencadeou maior interação, aproximação e relacionamento empático entre eles. A modificação dos pais no modo de abordar o filho, dando maior atenção e tendo mais disponibilidade para ouvi-lo conduziu ao envolvimento e cumplicidade mútua entre eles e a harmonia familiar, antes inexistente. A harmonia na família foi evidenciada pelo clima de compreensão, colaboração e diálogo entre todos, com diminuição das brigas e discussões, e por não precisarem mais aplicar castigo físico a HC.

A mudança na maneira de se relacionar com HC. diminuindo as cobranças e as punições permitiu que o vissem com um olhar mais generoso, e entenderam a fase em que ele se encontrava. Ao abrirem espaço para as manifestações de sentimentos, expressão de emoções e para 
conversações na família, conseguiram proporcionar ao filho HC. e à família momentos de escuta atenta às suas necessidades.

O processo de comunicação foi restabelecido, e a família compreendeu melhor o que estava acontecendo, sentindo-se mais esclarecida e confiante em sua capacidade para manejar o relacionamento familiar, o despertar da sexualidade de HC., para reorganizar-se e para prosseguir com esperança e perspectiva otimista de futuro. As interações familiares foram modificadas, sendo possível aos membros reunirem-se em família para falar sobre os relacionamentos conturbados. Desta maneira, começaram a se conhecer melhor e a entender as necessidades individuais e da família como um todo, indo em busca de soluções conjuntas e colaborativas.

A família engajou-se no desejo de promover mudanças, tornando-se fortalecida e com sua competência retomada para enfrentar os desafios e buscar de forma compartilhada novas maneiras de agir e manejar os relacionamentos, o despertar da sexualidade do filho e a crise familiar provocada pelo contexto da deficiência mental e pela experiência de sofrimento. As interações estabelecidas pela família, com base em sua participação no PIFCDM, evidenciaram que ela redefiniu os significados e passou a priorizar o bem estar de todos na família antes direcionado quase que, exclusivamente, a atender as demandas emergidas pelo contexto da deficiência mental do filho. A família identificou suas habilidades, percebeu-se forte e com autonomia para tomar decisões, resistir ao estresse e reorganizar-se para se adaptar e lidar de maneira mais eficiente com a vida familiar.

\section{CONSIDERAÇÕES FINAIS}

O objetivo deste artigo foi apresentar o Marco Teórico proposto para guiar as intervenções com família oferecidas em um programa de intervenção com família de crianças com deficiência mental a fim de promover suas forças e fortalecer sua resiliência. O Programa de Intervenção com Família - PIFCDM construído foi fundamentado em um Marco Teórico que foi embasado no Interacionismo Simbólico, no Modelo de Vulnerabilidade da Família e no Modelo de Resiliência. Ele foi desenvolvido para conduzir o processo de atendimento à família, com o foco em sua experiência, e para direcionar o planejamento das intervenções de enfermagem, a fim de ajudar a família a ter sua vulnerabilidade minimizada e sua resiliência potencializada. 
Uma das recomendações de Bell, Wright (2007) para novas pesquisas em enfermagem da família é a necessidade de identificar modelos teóricos e conceituais a serem usados para desenvolver intervenções, bem como para avaliar resultados. Ganong (2011) propõe que haja maior interesse em estudos sistematizados sobre o processo de intervenções em que se dê respostas sobre como as intervenções funcionam na família e quais mudanças desencadeiam em seus membros.

De acordo com Weihs, Fisher, Baird (2002) programas que envolvem elementos de didática, informação e construção das habilidades da família para a resolução de seus problemas, estímulo à comunicação, manejo de conflitos e reestruturação da compreensão cognitiva e emocional sobre a situação vivida, favorecem as relações familiares e o alívio do sofrimento. Ao focar os problemas de relacionamento em meio à crise, as intervenções podem aliviar os membros da família pressionados pelos desafios e dilemas vivenciados (CHESLA, 2010).

Considerando que a enfermeira tem como responsabilidade moral envolver-se com a família, a fim de ajudá-la a ter seu sofrimento amenizado, este estudo foi congruente e vai ao encontro do objetivo e do compromisso com uma prática de enfermagem avançada com famílias e com uma enfermagem honrosa, que se aprimora por desenvolver mecanismos para aliviar o sofrimento emocional, físico e espiritual dos pacientes e suas famílias.

O PIFCDM contribui para aquisição de conhecimento especializado e desenvolvimento de habilidades que podem ajudar a enfermeira a cuidar de famílias, vivendo o contexto da deficiência mental de um filho, a explorar as fontes de sofrimento e propor intervenções para aliviá-las. No processo de implantação de programas de intervenções de enfermagem à família no contexto da deficiência mental, destacamos a importância da relação que deve ser estabelecida entre a enfermeira e a família.

Acreditamos que a aplicação de um programa de intervenções com a abordagem direcionada às interações familiares traga benefícios que irão além de responder apenas às necessidades e demandas da família, mas promover suas habilidades e forças como sistema e unidade de interação, e traga satisfação à enfermeira que pode contribuir positivamente para que famílias vivendo contextos extremos de adversidades sejam amparadas, tenham seu sofrimento aliviado e sejam fortalecidas em sua experiência e história. 


\section{REFERÊNCIAS}

Angelo, M. (1997). Com a família em tempos difíceis: uma perspectiva de enfermagem. Tese (livre-docência). São Paulo: Escola de Enfermagem da USP.

Angelo, M. Bousso, R.S. (2001). Fundamentos da assistência à família em saúde: manual de enfermagem. In: BRASIL. Ministério da Saúde. Manual de enfermagem. Brasília: Ministério da Saúde, p. 14-17.

Barbosa, M.A.M. (2000). Compreendendo o mundo-vida da mãe com um filho deficiente. [Dissertação]. São Paulo: Universidade Federal de São Paulo.

Barbosa, M.A.M., Chaud, M.N., Gomes, M.M.F. (2008). Experiences of mothers of disabled children: a phenomenological study. Acta Paul. Enfermagem, 21(1): 46-52.

Barbosa, M.A.M, Pettengill, M.A.M; Farias, T.L., Lemos, L.C. (2009). Cuidado da criança com deficiência: suporte social acessado pelas mães. Rev. Gaúcha Enferm., 3: 406-412.

Bell, J.M., Wright, L.M. (2007). La recherche sur la pratique des soins infirmiers a la famille [Research on family interventions]. In F. Duhamel (Ed.), La santé et la famille: Une approche systémique en soins infirmiers [Families and health: A systemic approach in nursing care] (2nd ed.). Montreal, Quebec, Canada: Gaetan Morin editeur, Chenelière Éducation.

Blumer, H. (1969). Symbolic interactionism: perspective and method. Englewood Cliffs: Prentice Hall.

Chesla, C. (2010). Do Family Interventions Improve Health? J Fam Nurs; 16(4): 355-377.

Ganong, L. (2011). Return of the "Intimate Outsider": current trends and issues in family nursing research revisited. J Fam Nurs. 17(4): 416-440.

Guiller, C.A., Dupas, G.; Pettengill, M.A.M. (2007). Criança com anomalia congenital: estudo bibliográfico de publicações na área de enfermagem pediátrica. Acta Paul Enferm. 20(1):18-23.

Hasting, R.P, Beck, A., Hill, C. (2005). Positive contribuitions made by children with an intellectual disability in the family: mother and fathers perceptions. J Intellect Disabil. 9(2), 155-65.

Holanda, E.R., Collet, N., Costa, S.F.G. (2008). Crianças com Síndrome de Down: o significado do cuidar na percepção de mães. Online Brazilian Journal of Nursing. [online]. 7(2).

Madsen, W.C. (2010). Terapia colaborativa com famílias multiestressadas. 2.ed. São Paulo: Roca.

Marcheti, M.A. (2012). Programa de intervenção na família no contexto da deficiência mental: um espaço para promover mudanças. Tese (Doutorado) - Escola Paulista de Enfermagem da Universidade Federal de São Paulo, São Paulo. 249 p.

Marcheti, M.A., Mandetta, M.A. Marco Teórico do Programa de Intervenção com Família no Contexto da Deficiência: integrando o Interacionismo Simbólico e os conceitos de Vulnerabilidade da família e Resiliência. Atas CIAIQ2016. Investigação Qualitativa em Educação//Investigación Cualitativa en Educación//Volume1.

Pettengill, M.A.M. (2003). Vulnerabilidade da família: desenvolvimento do conceito. Tese (Doutorado) - Escola de Enfermagem da Universidade de São Paulo, São Paulo. 164p.

Pettengill, M.A.M, Angelo, M. (2005). Vulnerabilidade da família: desenvolvimento do conceito. Rev Latino-am Enfermagem; novembro-dezembro; 13(6):982-8.

Pettengill, M.A.M, Angelo, M. (2006). Identificação da vulnerabilidade da família na prática clínica. Revista da Escola de Enfermagem da USP. 40; 280-285. 
Pereira-Silva, N.L., Dessen, M.A. (2002). O que significa ter uma criança com deficiência mental na família. Educar, Curitiba. Editora UFPR, 23, 161-183.

Robinson, C.A., Wright, L.M. (1995). Family nursing interventions: what families say makes a difference. J Fam Nurs. 1(2): 327-45.

Scorgie, k.; Wilgosh, L., Sobsey, D. (2004). The experience of transformation in parents of children with disabilities: Theoretical considerations. Developmental Disabilities Bulletin, 32 (1), 84-110.

Sunelaitis, R. C.; Aarruda, D. C., Marcom, S.S. (2007). A repercussão de um diagnóstico de síndrome de Down no cotidiano familiar: perspectiva da mãe. Acta paul. enferm. [online]. 20(3), 264-271.

Svavarsdottir, EK. Listening to the Family's Voice: Nordic Nurses' Movement Toward Family Centered Care. J Fam Nurs $2006 ; 12 ; 346-367$.

Walsh, F. (2005). Fortalecendo a Resiliência Familiar. São Paulo: Roca.

Weihs, K.L.; Fisher, L, Baird, M. (2002). Families, health and behavior. A section of the Commissioned Report by the Committee on Health and Behavior: Research, Practice, and Policy, Division of Neuroscience and Behavioral Health and Division of Health Promotion and Disease Prevention, Institute of Medicine, National Academy of Sciences. Families, Systems \& Health; 20(1): 7-4.

Wright, L.M., Leahey, M. Concepts of family intervening. Em: Nurses and families: a guide to family assessment and intervention. Philadelphia: F.A. Davis, 1994. p. 1-21.

Wright, L.M. (2005). Spirituality, suffering, and illness: ideas for healing. Philadelphia: F.A. Davis.

Wright, L.M., Leahey, M. (2008). Enfermeiras e famílias: um guia para avaliação e intervenção na família. 4. ed. São Paulo: Roca. 